\title{
Acute $\Delta^{9}$-tetrahydrocannabinol blocks gastric hemorrhages induced by the nonsteroidal anti-inflammatory drug diclofenac sodium in mice
}

\author{
Steven G. Kinsey ${ }^{\mathrm{a}}$ and Erica C. Cole ${ }^{\mathrm{a}}$ \\ aDepartment of Psychology, West Virginia University, Morgantown, WV USA
}

\begin{abstract}
Nonsteroidal anti-inflammatory drugs (NSAIDs), which are among the most widely used analgesics in the world, cause gastrointestinal inflammation that is potentially life-threatening. Although inhibitors of endocannabinoid catabolic enzymes protect against gastropathy in fasted NSAID-treated mice, the gastroprotective effects of $\Delta^{9}$-tetrahydrocannabinol (THC), the primary psychoactive component of marijuana, have yet to be investigated. Male C57BL/6J mice were fasted, administered vehicle or $\Delta^{9}$-THC $(.01-50 \mathrm{mg} / \mathrm{kg}$; oral or intraperitoneal), and then treated with the NSAID diclofenac sodium (100 mg/kg, p.o.) to induce gastric lesions. In separate groups of mice, the cannabimimetic behavioral effects of $\Delta^{9}$-THC given via each route of administration were compared using a battery of tests, consisting of assessment of locomotor activity, nociception in the tail withdrawal test, catalepsy in the bar test, and hypothermia. $\Delta^{9}$-THC dose-dependently attenuated diclofenac-induced gastric hemorrhagic streaks through both p.o. and i.p. routes of administration $\left(\mathrm{ED}_{50}(95 \%\right.$ confidence interval $)=0.64(0.26-1.55) \mathrm{mg} / \mathrm{kg}$ and $0.06(0.01-0.34)$ $\mathrm{mg} / \mathrm{kg}$, respectively). $\Delta^{9}$-THC given i.p. was $2-3$ orders of magnitude more potent in reducing diclofenac-induced gastric ulcers than in producing locomotor immobility, antinociception, hypothermia, and catalepsy, while the potency of ratio of p.o. $\Delta^{9}$-THC between each behavior measure was 7-18. These data indicate that the phytocannabinoid $\Delta^{9}$-THC protects against diclofenac-induced gastric inflammatory tissue damage at doses insufficient to cause common cannabinoid side effects.
\end{abstract}

\section{Keywords}

Cannabinoid; gastric inflammation; NSAID dyspepsia; cyclooxygenase; diclofenac; tetrahydrocannabinol

(C) 2013 Elsevier B.V. All rights reserved.

Corresponding author: Steven G. Kinsey, PhD, P.O. Box 6040, Morgantown, WV 26506-6040, Phone: +1 (304) 293-1685, Fax: +1(304) 293-6606, sgkinsey@mail.wvu.edu.

Publisher's Disclaimer: This is a PDF file of an unedited manuscript that has been accepted for publication. As a service to our customers we are providing this early version of the manuscript. The manuscript will undergo copyediting, typesetting, and review of the resulting proof before it is published in its final citable form. Please note that during the production process errors may be discovered which could affect the content, and all legal disclaimers that apply to the journal pertain.

Disclosures

No competing interests declared.

Contributions: SGK \& ECC performed the research and wrote the paper; SGK designed the research study and analyzed the data. 


\section{Introduction}

Nonsteroidal anti-inflammatory drugs (NSAIDs) are widely used analgesics that have gained attention as a leading cause of gastric pathology (Musumba et al., 2009). Roughly $60-70 \%$ of patients chronically taking NSAIDs develop at least one GI issue during the course of treatment. Not surprisingly, NSAID-induced dyspepsia is the leading cause of noncompliance (Lanas, 2009). NSAIDs cause GI bleeding, erosion of gastric mucosa, and ulcers, by mechanisms that are not entirely understood but appear to involve inhibiting prostaglandins formation in the GI tract that are responsible for regulating gastric acid secretion and maintaining gastric mucosal integrity by producing mucus (Singh, 1998). In addition to injuring the gastric lining, NSAIDs prevent repair and regeneration of gastric endothelial cells, which further delays ulcer healing (Musumba et al., 2009). NSAID consumption can increase stomach permeability within 12 hours, and although this damage can be reversed in 12 hours, the longer the patient has used NSAIDs the longer it takes to reverse (Lanas, 2009). To protect against this common side effect, chronic NSAID users are routinely co-prescribed proton pump inhibitors and other antacids. However, controversy exists over whether long-term use of proton pump inhibitors may have undesirable effects as well, including increased risk for gastric polyps, cancer, bone fractures, bacterial infections, and vitamin deficiencies (Lodato et al., 2010).

Cannabis sativa and its extracts have been used for thousands of years to treat a variety of health issues (Mechoulam and Parker, 2013). The primary psychoactive element in marijuana, $\Delta^{9}$-tetrahydrocannabinol (THC) (Gaoni and Mechoulam, 1964), produces analgesia, anti-inflammation, anti-convulsion, anxiolysis, and anti-emesis (Pertwee, 2012). $\Delta^{9}$-THC binds to cannabinoid receptor $1\left(\mathrm{CB}_{1}\right)$ and cannabinoid receptor $2\left(\mathrm{CB}_{2}\right) . \mathrm{CB}_{1}$ receptors are expressed throughout the central, peripheral, and enteric nervous systems, and are responsible for the psychoactive effects of cannabinoid agonists. $\mathrm{CB}_{2}$ receptors are associated with the immune system and are expressed in macrophages, microglia, and at low levels on neurons, and play a predominantly anti-inflammatory role (Dembinski et al., 2006).

Cannabinoids slow gastric emptying (Izzo and Sharkey, 2010) and possess gastroprotective properties (Di Marzo and Piscitelli, 2011; Pertwee, 2001). For example, high dose $\Delta^{9}$-THC $(100 \mathrm{mg} / \mathrm{kg}$, s.c.) prevented gastric ulceration in Sprague-Dawley rats subjected to gastric pylorus ligation (Sofia et al., 1978). Similarly, a relatively high dose of $\Delta^{9}-\mathrm{THC}(10 \mathrm{mg} / \mathrm{kg}$, i.p.) blocked the development of gastric hemorrhages induced by the NSAID diclofenac in mice (Kinsey et al., 2011b). Pretreatment with the $\mathrm{CB}_{1}$ receptor antagonist rimonabant blocked the gastroprotective effects of $\Delta^{9}$-THC, indicating $\mathrm{CB}_{1}$ receptor mediation.

Although previous reports (Kinsey et al., 2011b; Sofia et al., 1978) indicate that high doses of $\Delta^{9}$-THC prevent gastric tissue damage, questions remain about the potency of $\Delta^{9}$-THC in preventing gastric lesions caused by NSAID treatment. The objective of the present study was to test the hypothesis that $\Delta^{9}$-THC blocks NSAID-induced gastric hemorrhages at doses that are insufficient to cause overt cannabimimetic behavioral alterations. To this end, we assessed the potency of $\Delta^{9}$-THC doses via intraperitoneal and oral routes of administration to prevent gastric hemorrhages induced by the NSAID diclofenac sodium. Diclofenac was 
chosen not only because this model is well established in mice, but also because it is a commonly prescribed NSAID, due to its relatively low incidence of gastric side effects (Patrono and Baigent, 2009). Additionally, the relative potency of $\Delta^{9}$-THC through both routes of administration was assessed in the "tetrad" test battery, consisting of locomotor, analgesic, cataleptic, and hypothermic tests. $\Delta^{9}$-THC dose-dependently blocked gastric hemorrhages at lower doses than those needed to elicit measurable cannabinoid effects on behavior or hypothermia.

\section{Material and Methods}

\subsection{Animals}

Experimentally naïve male C57BL/6J mice (Jackson Labs, Bar Harbor, ME, USA) approximately 10 weeks of age at the start of the experiment served as subjects $(\mathrm{N}=209)$. Mice were housed 3-5 per cage on corncob bedding in a temperature $\left(21 \pm 2^{\circ} \mathrm{C}\right)$ and humidity controlled environment, with free access to food and water, and were randomly assigned to each experimental group. The Institutional Animal Care and Use Committees at West Virginia University and Virginia Commonwealth University approved all experimental protocols. Data reported are in accordance with ARRIVE guidelines for reporting experiments involving animals.

\subsection{Gastric Lesions}

Gastric ulcers were induced as described previously (Kinsey et al., 2011b; Nomura et al., 2011). Briefly, mice were weighed and food deprived with free access to water for $23 \mathrm{~h}$ prior to $\Delta^{9}$-THC administration. A wire grate was placed $3 \mathrm{~cm}$ above the cage floor in each of the cages to prevent the consumption of the cob bedding or feces. At $23 \mathrm{~h}$ after food removal, the mice were administered $\Delta^{9}$-THC or vehicle. One hour later, diclofenac sodium (100 mg/kg, p.o.) was administered to induce gastric hemorrhages, and the mice were returned to their home cages. At six hours, the mice were euthanized via $\mathrm{CO}_{2}$ asphyxia and stomachs were quickly harvested, cut along the greater curvature, rinsed with distilled water, placed on a lighted tracing table (Artograph light pad 1920) and photographed (Canon T3 Rebel digital camera with a 10x close up lens). Image files were renamed, and an experimenter blinded to treatment conditions quantified the gastric hemorrhages, relative to a $1 \mathrm{~mm}$ reference in each photo, using Adobe Photoshop (version CS5). The length of each hemorrhagic streak was marked with a straight, 1 pixel wide line. The total number of marked pixels was quantified using the histogram function. This process was repeated for a $1 \mathrm{~mm}$ reference that was in each photograph. Finally, the pixels total from the hemorrhage lengths was divided by the pixel total of the $1 \mathrm{~mm}$ reference, resulting in an objective measure of total hemorrhages, in $\mathrm{mm}$, per stomach.

\subsection{Tetrad battery}

A separate group of mice was assessed for cannabinoid sensitive changes in catalepsy, antinociception, locomotor activity, and body temperature, as described previously (Schlosburg et al., 2010). The experimenter for each test was blinded to the treatment conditions. 
2.3.1 Catalepsy-Catalepsy was evaluated using the bar test, in which the front paws of each subject were placed on a rod $(0.75 \mathrm{~cm}$ diameter) that was elevated $4.5 \mathrm{~cm}$ above the surface of the bench. After administration of drug or vehicle, the mouse's front paws were placed on an elevated bar for a duration of up to 60 seconds. Periods of immobility (i.e., catalepsy, the absence of voluntary movement) are scored. If the animal moved away from the bar on three occasions, the test was ended.

2.3.2 Tail Immersion test-Individual mice were placed head first into a small cone fabricated from absorbent under pads (VWR Scientific Products; $4 \mathrm{~cm}$ diameter, $11 \mathrm{~cm}$ length) with the tail exposed. The experimenter gently held the mouse and immersed $1 \mathrm{~cm}$ of the distal end of the tail into a $56.0^{\circ} \mathrm{C}$ water bath. The latency for the mouse to withdraw its tail from the water was recorded. Tails were immersed for a maximum of $10 \mathrm{~s}$, to avoid possible tissue damage.

2.3.3 Spontaneous locomotor activity.-Individual mice were placed in a clear Plexiglas box $(42.7 \times 21.0 \times 20.4 \mathrm{~cm})$, and locomotor activity was assessed for $5 \mathrm{~min}$. Anymaze software (Stoelting, Wood Dale, IL, USA) was used to determine the percentage of time spent immobile after exposure to either vehicle or $\Delta^{9}$-THC.

2.3.4 Hypothermia-Body temperature was determined using a microprobe thermometer (BAT-12, Physitemp Instruments Inc., Clifton, NJ, USA) with a thermocouple probe designed for rectal temperature (inserted approximately $2 \mathrm{~cm}$ ). Body temperature was recorded immediately prior to (baseline), and at $1 \mathrm{~h}$ following $\Delta^{9}$-THC administration. Differences between rectal temperatures before and after $\Delta^{9}$-THC administration were calculated for each mouse.

\subsection{Drugs}

Diclofenac sodium was purchased from Sigma (St. Louis, MO, USA) and $\Delta^{9}$ Tetrahydrocannabinol (THC) was acquired via the National Institute on Drug Abuse Drug Supply Program (Bethesda, MD, USA). Both compounds were dissolved in a vehicle consisting of 1:1:18 parts ethanol, Emulphor (alkamuls-620; Sanofi-Aventis, Bridgewater, $\mathrm{NJ}$, USA), and normal saline (i.e., $0.9 \% \mathrm{NaCl}, \mathrm{pH} 7.0$ ). Solutions were warmed to room temperature prior to administration and injected in a volume of $10 \mu \mathrm{l} / \mathrm{g}$ body mass.

\subsection{Data Analysis}

All data are reported as mean \pm S.E.M.. Gastric hemorrhage data were analyzed using oneway between subjects analysis of variance (ANOVA), and behavioral data were analyzed using two-way between subjects ANOVA. Dunnett's post hoc test was used to compare each $\Delta^{9}$-THC dose to vehicle. The $\mathrm{ED}_{50}$ values with $95 \%$ confidence intervals of $\Delta^{9}$-THC were determined by least-squares linear regression analysis on the logs of the doses. Potency ratios comparing $\Delta^{9}$-THC's gastroprotective vs. cannabinoid sensitive effects were made as described previously (Colquhoun, 1971). Differences were considered statistically significant if $\mathrm{P}<0.05$. 


\section{Results}

\section{1 $\Delta^{9}$-THC blocks diclofenac-induced gastric hemorrhages}

Intraperitoneal administration of $\Delta^{9}$-THC dose-dependently attenuated gastric hemorrhages $\left[\mathrm{F}(7,55)=10.1 ; \mathrm{P}<0.0001 ;\right.$ Fig. 1]. Post hoc analyses revealed that intraperitoneal $\Delta^{9}$-THC attenuated diclofenac-induced gastric hemorrhages at $\geq 0.1 \mathrm{mg} / \mathrm{kg}$. Similarly, oral administration of $\Delta^{9}$-THC also dose-dependently attenuated gastric hemorrhages $[F(5,50)=$ 8.3; P $<0.0001$; Fig. 1]. Post hoc analyses revealed that oral $\Delta^{9}$-THC attenuated diclofenacinduced gastric hemorrhages at $\geq 2.5 \mathrm{mg} / \mathrm{kg}$, p.o. Representative images of stomachs from these studies are shown in Fig. 2. Although not tested in the present study, vehicle-treated mice do not typically spontaneously develop gastric hemorrhages (Kinsey et al., 2011b; Naidu et al., 2009; Nomura et al., 2011).

\subsection{Intraperitoneal and oral administration elicit $\Delta^{9}$-THC-sensitive behaviors}

In order to determine the relative potency between the gastroprotective effects and cannabimimetic side effects of $\Delta^{9}$-THC, separate groups of mice were administered $\Delta^{9}$-THC (i.p. or p.o.) and tested in the tetrad assay. $\Delta^{9}$-THC increased immobility $[\mathrm{F}(5,84)=93.3 ; \mathrm{P}$ $<0.0001$; Fig. 3A] at $\geq 5 \mathrm{mg} / \mathrm{kg}$, increased catalepsy $[\mathrm{F}(5,84)=48.2 ; \mathrm{P}<0.0001 ;$ Fig. 3B] at $\geq 10 \mathrm{mg} / \mathrm{kg}$, increased tail withdrawal latency $[\mathrm{F}(5,84)=9.94 ; \mathrm{P}<0.0001 ; \mathrm{Fig} .3 \mathrm{C}]$ at $\geq 10$ $\mathrm{mg} / \mathrm{kg}$, and increased hypothermia $[\mathrm{F}(5,84)=41.6 ; \mathrm{P}<0.0001 ; \mathrm{Fig} .3 \mathrm{D}]$ at $\geq 5 \mathrm{mg} / \mathrm{kg}$. However, route of administration did not significantly affect $\Delta^{9}$-THC sensitive behaviors, including locomotor activity $(\mathrm{p}=0.24)$, catalepsy $(\mathrm{p}=0.10)$, tail withdrawal latency $(\mathrm{p}=$ $0.59)$, or hypothermia $(\mathrm{p}=0.21)$.

\section{Discussion}

GI complications occur in $1 \%-1.5 \%$ of NSAID users within the first year of treatment (Lanas, 2009). Approximately 107,000 people per year in the USA are admitted to a hospital for gastrointestinal complications due to the frequent use of NSAIDs. In particular, osteoarthritis and rheumatoid arthritis patients are about 5 times more likely to be hospitalized than the general population because of ulcerogenic side effects related to their use of NSAIDs (Singh, 1998). Moreover, GI complications associated with NSAID use account for approximately 16,500 of the 107,000 annual deaths in this patient population (Singh, 1998). For these reasons, it is imperative that advancements be made in the prevention of NSAID-induced gastrointestinal pathology. In the present study, $\Delta^{9}$-THC potently blocked gastric hemorrhages at doses at least 100 fold lower than have been previously reported (Kinsey et al., 2011b).

Of particular interest, these gastroprotective effects were observed at doses that did not cause classic cannabinoid effects on measures of locomotor activity, analgesia, or body temperature (data summarized in Table 1). Intraperitoneal $\Delta^{9}$-THC administration effectively blocked gastric hemorrhages at lower doses than oral $\Delta^{9}$-THC administration. However, the cannabinoid effects of higher doses of $\Delta^{9}$-THC were evident regardless of route of administration. However, it is notable that the oral administration significantly attenuated the gastric hemorrhages at $\geq 2.5 \mathrm{mg} / \mathrm{kg}$, immobility and hypothermia increased at 
$\geq 5 \mathrm{mg} / \mathrm{kg}$, indicating that some psychoactive effects may occur at doses near the antihemorrhagic threshold.

The gastroprotective effect of high-dose $\Delta^{9}$-THC (i.e., $10 \mathrm{mg} / \mathrm{kg}$, i.p.) treatment is blocked by pretreatment with the $\mathrm{CB}_{1}$ receptor antagonist rimonabant, whereas the $\mathrm{CB}_{2}$ receptor selective antagonist $\mathrm{SR} 144528$ is without effect, indicating the involvement of $\mathrm{CB}_{1}$, and not $\mathrm{CB}_{2}$ (Kinsey et al., 2011b). The same pattern of effects was reported in rats, where the synthetic cannabinoid receptor agonist WIN55,212 blocked stress-induced gastric ulcers in rats via $\mathrm{CB}_{1}$ (Germano et al., 2001). Although $\mathrm{CB}_{2}$ receptor agonists are known to produce anti-inflammatory effects (Kinsey et al., 2011a; Mackie, 2006), $\mathrm{CB}_{1}$ is expressed on acid producing pyramidal cells (Pazos et al., 2008). Also in support of a $\mathrm{CB}_{1}$ receptor-mediated mechanism of action, the synthetic cannabinoid receptor agonists HU-210 and WIN55,212 decrease pentagastrin-induced gastric acid production in sedated rats (Adami et al., 2002; Adami et al., 2004), suggesting that $\mathrm{CB}_{1}$ receptor activation directly reduces acid production, and concomitantly reduces gastric inflammation. Indeed, regular users of marijuana have lower gastric acid production than non-users (Nalin et al., 1978).

Although $\mathrm{CB}_{1}$ receptors appear to be physiologically relevant in modulating cannabinoid effects, the contribution these receptors localized to nervous vs. non-nervous tissue is controversial. In rats, intracerebroventricular (i.c.v.) administration of anandamide or its chiral analog, methanandamide, protected against ethanol-induced gastric ulceration, and these effects were prevented by rimonabant pretreatment (Shujaa et al., 2009). I.C.V. administration of rimonabant also blocked the gastroprotective effects of intravenous methanandamide, again implicating the involvement of centrally located $\mathrm{CB}_{1}$ receptors in the gastroprotective effects of cannabinoids (Shujaa et al., 2009). However, in mice, the peripherally restricted FAAH inhibitor URB937, which increases anandamide levels in peripheral tissues and not the brain, significantly reduced the number and severity of indomethacin-induced gastric ulcers, indicating that peripherally located cannabinoid receptors modulate the gastroprotective effects of anandamide (Sasso et al., 2012). In agreement with these data, i.v., but not i.c.v. administration of synthetic cannabinoid receptor agonists reduced pentagastrin-induced gastric acid secretion in sedated rats, suggesting a peripheral cannabinoid receptor mechanism (Adami et al., 2004).

In addition to the cannabinoid receptors, $\Delta^{9}$-THC also binds to other $\mathrm{G}$ proteincoupled receptors, including GPR18 and GPR55. Although there evidence that either GPR18 or GPR55 modulate gastric inflammation is currently lacking, GPR55 is expressed in the brain (Sawzdargo et al., 1999) and gut (Schicho et al., 2011), as well as immune cells including neutrophils (Balenga et al., 2011), and thus it is possible that it could influence gastric function (Schicho and Storr, 2012), especially in the presence of high doses of $\Delta^{9}$-THC.

The present data indicate that, although $\Delta^{9}$-THC much more potently blocked gastric lesions when administered intraperitoneally than when administered orally, either route of administration was equipotent on cannabinoid sensitive effects, as assayed in the tetrad battery. These tetrad data are in agreement with previously published reports (Falenski et al., 2010; Kinsey et al., 2013; Long et al., 2010). For example, acute administration of $10 \mathrm{mg} / \mathrm{kg}$ $\Delta^{9}$-THC (but not $\leq 3 \mathrm{mg} / \mathrm{kg}$ ) significantly increased hypothermia and catalepsy, and reduced 
the overall distance traveled in the open field test (Long et al., 2010). Although these authors did not report any significant analgesic effects of $\Delta^{9}$-THC in the tail immersion test, this is most likely due to subtle methodological differences. Moreover, the $\mathrm{ED}_{50}$ values for THC treatment in the present study are also within the same range as those previously reported in the tetrad following i.p. administration of $\Delta^{9}$-THC (Falenski et al., 2010).

The reduced potency of $\Delta^{9}$-THC in attenuating gastric hemorrhages may be explained by the extensive "first-pass" metabolism of orally administered $\Delta^{9}$-THC (Nadulski et al., 2005).

However, the lack of a route of administration effect in the tetrad tests was somewhat unexpected. Although oral and intraperitoneal routes of administration have not been directly compared in the tetrad battery, i.p. administration is less potent than i.v. administration (Wiley and Martin, 2003). It is possible that the disparity of $\Delta^{9}$-THC effects in the gastric hemorrhage model and the tetrad tests are due to different pharmacokinetic effects in either model. The peripherally restricted FAAH inhibitor URB937 attenuates indomethacin-induced gastric ulcers, providing evidence for a mechanism that does not require cannabinoid receptors in the central nervous system (Sasso et al., 2012), in contrast to tetrad effects which are governed by the central nervous system.

Although the present data indicate that $\Delta^{9}$-THC significantly attenuates gastric lesions caused by the NSAID diclofenac, it is worth noting some limitations of the model. First, the mice in the present study were fasted and subjected to acute administration of diclofenac, whereas extreme complications arising from NSAIDs tend to occur following chronic administration in humans. Second, $\Delta^{9}$-THC was administered prior to diclofenac, which does not provide conclusive evidence that cannabinoids reverse gastric damage caused by NSAIDs. Third, because of metabolic differences between mice and humans, the doses of $\Delta^{9}$-THC or diclofenac chosen for the present study may not necessarily extrapolate to appropriate doses for human populations. Regardless, these data are consistent with previous reports that $\Delta^{9}$-THC has anti-inflammatory effects in the stomach of rats (Sofia et al., 1978), mice (Kinsey et al., 2011b), and humans (Nalin et al., 1978).

The results of the present study suggest that $\Delta^{9}$-THC, which is approved by the US Food and Drug Administration (i.e., dronabinol capsules) to treat cancer chemotherapy-induced nausea and emesis and AIDS-related cachexia, may also possess gastroprotective effects in NSAID using patients. Given that the potency ratio of gastric of orally administered $\Delta^{9}$-THC was considerably lower than that of intraperitoneally administered $\Delta^{9}$-THC, future studies are needed shed light on whether this lower potency also indicates a relatively limited therapeutic window for oral administration of $\Delta^{9}$-THC that avoids psychoactive effects. As current antacid regimens may be associated with undesirable effects, such as reduced bone density, increased risk of bacterial infection, and vitamin deficiencies (Lodato et al., 2010), other approaches to prevent NSAID-induced gastric ulcers are needed. In addition to their gastroprotective effects, cannabinoids produce other beneficial effects, including pain reduction. Specifically, endocannabinoid modulators (e.g., FAAH inhibitors) not only have analgesic effects on their own, but augment the analgesic effects of NSAIDs, including diclofenac and indomethacin, in mice (Naidu et al., 2009; Sasso et al., 2012). Thus, cannabinoids may have the added benefit of reducing the effective analgesic dose of NSAIDs, as well as reducing the incidence of NSAID-induced gastric ulcers. 


\section{Conclusions}

In fasted mice, the cannabinoid $\Delta^{9}$-THC significantly attenuated gastric hemorrhages induced by the nonsteroidal anti-inflammatory drug, diclofenac sodium. Intraperitoneal administration of $\Delta^{9}$-THC more potently reduced the severity of diclofenac-induced hemorrhages than oral administration, although either route of administration caused similar classical cannabinoid-sensitive effects.

\section{Acknowledgments}

\section{Funding}

We thank Lamont Booker, Scott O’Neal, Lakin Whitlatch, and Selena Engebretson for technical assistance. We are especially grateful to Aron Lichtman for design and editorial assistance. Financial support was provided by the National Institutes of Health, grants T32DA007027, P01DA017259, and P01DA009789.

\section{References}

Adami M, Frati P, Bertini S, Kulkarni-Narla A, Brown DR, de Caro G, Coruzzi G, Soldani G. Gastric antisecretory role and immunohistochemical localization of cannabinoid receptors in the rat stomach. Br J Pharmacol. 2002; 135:1598-1606. [PubMed: 11934799]

Adami M, Zamfirova R, Sotirov E, Tashev R, Dobrinova Y, Todorov S, Coruzzi G. Gastric antisecretory effects of synthetic cannabinoids after central or peripheral administration in the rat. Brain Res Bull. 2004; 64:357-361. [PubMed: 15561471]

Balenga NA, Aflaki E, Kargl J, Platzer W, Schroder R, Blattermann S, Kostenis E, Brown AJ, Heinemann A, Waldhoer M. GPR55 regulates cannabinoid 2 receptor-mediated responses in human neutrophils. Cell Res. 2011; 21:1452-1469. [PubMed: 21467997]

Colquhoun, D. Lectures on biostatistics; an introduction to statistics with applications in biology and medicine. Oxford: Clarendon Press; 1971.

Dembinski A, Warzecha Z, Ceranowicz P, Dembinski M, Cieszkowski J, Pawlik WW, Konturek SJ, Tomaszewska R, Hladki W, Konturek PC. Cannabinoids in acute gastric damage and pancreatitis. J Physiol Pharmacol. 2006; 57(Suppl 5):137-154. [PubMed: 17218765]

Di Marzo V, Piscitelli F. Gut feelings about the endocannabinoid system. Neurogastroenterol Motil. 2011; 23:391-398. [PubMed: 21481098]

Falenski KW, Thorpe AJ, Schlosburg JE, Cravatt BF, Abdullah RA, Smith TH, Selley DE, Lichtman AH, Sim-Selley LJ. FAAH-/- mice display differential tolerance, dependence, and cannabinoid receptor adaptation after delta 9-tetrahydrocannabinol and anandamide administration. Neuropsychopharm. 2010; 35:1775-1787.

Gaoni Y, Mechoulam R. Isolation, structure, and partial synthesis of an active constituent of hashish. J. Amer. Chem. Soc. 1964; 86:1646-1647.

Germano MP, D'Angelo V, Mondello MR, Pergolizzi S, Capasso F, Capasso R, Izzo AA, Mascolo N, De Pasquale R. Cannabinoid CB1-mediated inhibition of stress-induced gastric ulcers in rats. Naunyn Schmiedebergs Arch Pharmacol. 2001; 363:241-244. [PubMed: 11218077]

Izzo AA, Sharkey KA. Cannabinoids and the gut: new developments and emerging concepts. Pharmacol Ther. 2010; 126:21-38. [PubMed: 20117132]

Kinsey SG, Mahadevan A, Zhao B, Sun H, Naidu PS, Razdan RK, Selley DE, Imad Damaj M, Lichtman $\mathrm{AH}$. The $\mathrm{CB}(2)$ cannabinoid receptor-selective agonist $\mathrm{O}-3223$ reduces pain and inflammation without apparent cannabinoid behavioral effects. Neuropharmacology. 2011a; 60:244-251. [PubMed: 20849866]

Kinsey SG, Nomura DK, O'Neal ST, Long JZ, Mahadevan A, Cravatt BF, Grider JR, Lichtman AH. Inhibition of monoacylglycerol lipase attenuates nonsteroidal anti-inflammatory drug-induced gastric hemorrhages in mice. J Pharmacol Exp Ther. 2011b; 338:795-802. [PubMed: 21659471] 
Kinsey SG, Wise LE, Ramesh D, Abdullah R, Selley DE, Cravatt BF, Lichtman AH. Repeated Low Dose Administration of the Monoacylglycerol Lipase Inhibitor JZL184 Retains CB1 Receptor Mediated Antinociceptive and Gastroprotective Effects. J Pharmacol Exp Ther. 2013

Lanas A. Nonsteroidal antiinflammatory drugs and cyclooxygenase inhibition in the gastrointestinal tract: a trip from peptic ulcer to colon cancer. Am J Med Sci. 2009; 338:96-106. [PubMed: 19680014]

Lodato F, Azzaroli F, Turco L, Mazzella N, Buonfiglioli F, Zoli M, Mazzella G. Adverse effects of proton pump inhibitors. Best Pract Res Clin Gastroenterol. 2010; 24:193-201. [PubMed: 20227032]

Long LE, Chesworth R, Huang XF, McGregor IS, Arnold JC, Karl T. A behavioural comparison of acute and chronic Delta9-tetrahydrocannabinol and cannabidiol in C57BL/6JArc mice. Int J Neuropsychopharmacol. 2010; 13:861-876. [PubMed: 19785914]

Mackie K. Cannabinoid receptors as therapeutic targets. Annu Rev Pharmacol Toxicol. 2006; 46:101122. [PubMed: 16402900]

Mechoulam R, Parker LA. The endocannabinoid system and the brain. Annu Rev Psychol. 2013; 64:21-47. [PubMed: 22804774]

Musumba C, Pritchard DM, Pirmohamed M. Review article: cellular and molecular mechanisms of NSAID-induced peptic ulcers. Aliment Pharmacol Ther. 2009; 30:517-531. [PubMed: 19575764]

Nadulski T, Sporkert F, Schnelle M, Stadelmann AM, Roser P, Schefter T, Pragst F. Simultaneous and sensitive analysis of THC, 11-OH-THC, THC-COOH, CBD, and CBN by GC-MS in plasma after oral application of small doses of THC and cannabis extract. J Anal Toxicol. 2005; 29:782-789. [PubMed: 16356335]

Naidu PS, Booker L, Cravatt BF, Lichtman AH. Synergy between enzyme inhibitors of fatty acid amide hydrolase and cyclooxygenase in visceral nociception. J Pharmacol Exp Ther. 2009; 329:48-56. [PubMed: 19118134]

Nalin DR, Levine MM, Rhead J, Bergquist E, Rennels M, Hughes T, O'Donnel S, Hornick RB. Cannabis, hypochlorhydria, and cholera. Lancet. 1978; 2:859-862. [PubMed: 81411]

Nomura DK, Morrison BE, Blankman JL, Long JZ, Kinsey SG, Marcondes MC, Ward AM, Hahn YK, Lichtman AH, Conti B, Cravatt BF. Endocannabinoid hydrolysis generates brain prostaglandins that promote neuroinflammation. Sci. 2011; 334:809-813.

Patrono C, Baigent C. Low-dose aspirin, coxibs, and other NSAIDS: a clinical mosaic emerges. Mol Interv. 2009; 9:31-39. [PubMed: 19299662]

Pazos MR, Tolon RM, Benito C, Rodriguez CF, Gorgojo JJ, Nevado M, Alvarez M, Arias F, Almodovar F, Fernandez MT, Lledo JL, Gonzalez S, Fernandez-Ruiz JJ, Romero J. Cannabinoid CB1 receptors are expressed by parietal cells of the human gastric mucosa. J Histochem Cytochem. 2008; 56:511-516. [PubMed: 18285348]

Pertwee RG. Cannabinoids and the gastrointestinal tract. Gut. 2001; 48:859-867. [PubMed: 11358910]

Pertwee RG. Targeting the endocannabinoid system with cannabinoid receptor agonists: pharmacological strategies and therapeutic possibilities. Philos Trans R Soc Lond B Biol Sci. 2012; 367:3353-3363. [PubMed: 23108552]

Sasso O, Bertorelli R, Bandiera T, Scarpelli R, Colombano G, Armirotti A, Moreno-Sanz G, Reggiani A, Piomelli D. Peripheral FAAH inhibition causes profound antinociception and protects against indomethacin-induced gastric lesions. Pharmacol Res. 2012; 65:553-563. [PubMed: 22420940]

Sawzdargo M, Nguyen T, Lee DK, Lynch KR, Cheng R, Heng HH, George SR, O'Dowd BF. Identification and cloning of three novel human $\mathrm{G}$ protein-coupled receptor genes GPR52, PsiGPR53 and GPR55: GPR55 is extensively expressed in human brain. Brain Res Mol Brain Res. 1999; 64:193-198. [PubMed: 9931487]

Schicho R, Bashashati M, Bawa M, McHugh D, Saur D, Hu HM, Zimmer A, Lutz B, Mackie K, Bradshaw HB, McCafferty DM, Sharkey KA, Storr M. The atypical cannabinoid O-1602 protects against experimental colitis and inhibits neutrophil recruitment. Inflamm Bowel Dis. 2011; 17:1651-1664. [PubMed: 21744421]

Schicho R, Storr M. A potential role for GPR55 in gastrointestinal functions. Curr Opin Pharmacol. 2012; 12:653-658. [PubMed: 23063456] 
Schlosburg JE, Blankman JL, Long JZ, Nomura DK, Pan B, Kinsey SG, Nguyen PT, Ramesh D, Booker L, Burston JJ, Thomas EA, Selley DE, Sim-Selley LJ, Liu QS, Lichtman AH, Cravatt BF. Chronic monoacylglycerol lipase blockade causes functional antagonism of the endocannabinoid system. Nat Neurosci. 2010; 13:1113-1119. [PubMed: 20729846]

Shujaa N, Zadori ZS, Ronai AZ, Barna I, Mergl Z, Mozes MM, Gyires K. Analysis of the effect of neuropeptides and cannabinoids in gastric mucosal defense initiated centrally in the rat. J Physiol Pharmacol. 2009; 60(Suppl 7):93-100. [PubMed: 20388951]

Singh G. Recent considerations in nonsteroidal anti-inflammatory drug gastropathy. Am J Med. 1998; 105:31S-38S. [PubMed: 9715832]

Sofia RD, Diamantis W, Harrison JE, Melton J. Evaluation of antiulcer activity of delta9tetrahydrocannabinol in the Shay rat test. Pharmacol. 1978; 17:173-177.

Wiley JL, Martin BR. Cannabinoid pharmacological properties common to other centrally acting drugs. Eur J Pharmacol. 2003; 471:185-193. [PubMed: 12826237] 


\section{Diclofenac-induced gastric hemorrhages}

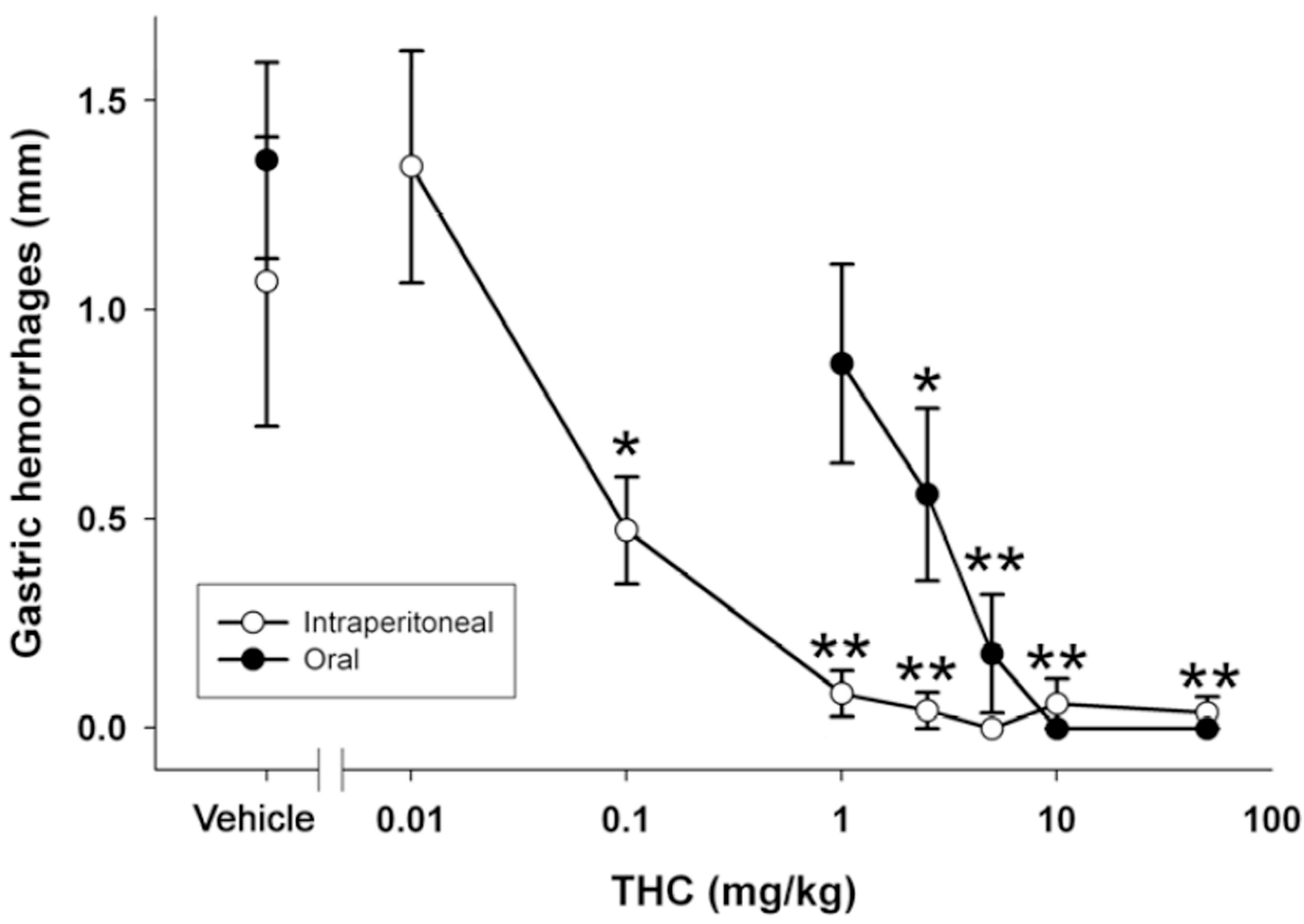

Fig. 1.

THC dose-dependently attenuates diclofenac-induced gastric hemorrhages. THC was administered intraperitoneally (i.p.) or orally (p.o.) $1 \mathrm{~h}$ before diclofenac sodium (100 $\mathrm{mg} / \mathrm{kg}$, p.o.) was administered in fasted mice. Data presented as mean \pm S.E.M. $(\mathrm{n}=7-8)$. Open circles: intraperitoneal $\Delta^{9}$-THC; closed circles: oral $\Delta^{9}-\mathrm{THC} * \mathrm{P}<0.05, * * \mathrm{P}<0.01$ vs. vehicle pretreatment. All mice were treated with diclofenac. 


\section{Vehicle (ip) + Diclofenac}

\section{Vehicle (po) + Diclofenac}

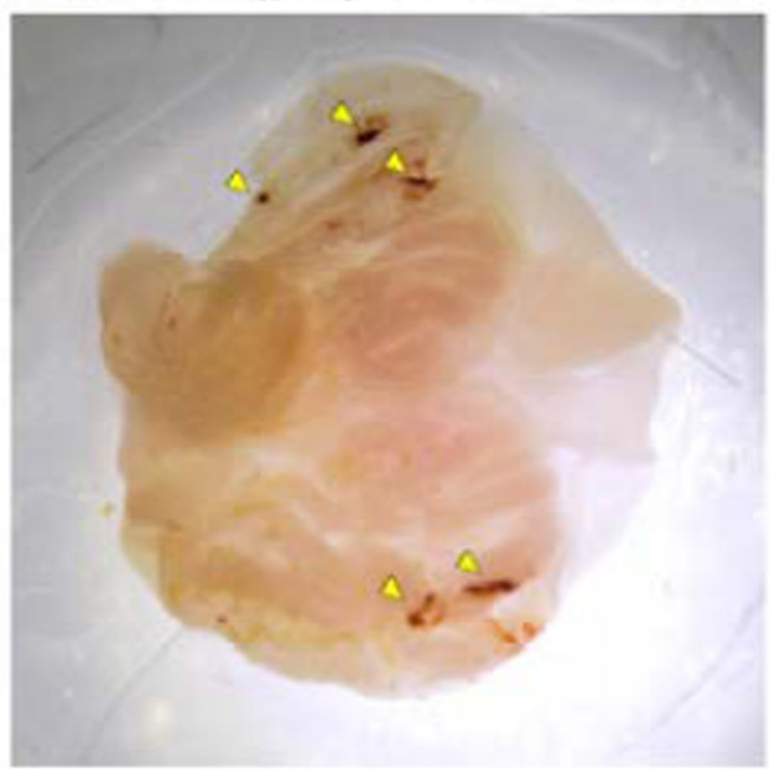

\section{THC (po) + Diclofenac}

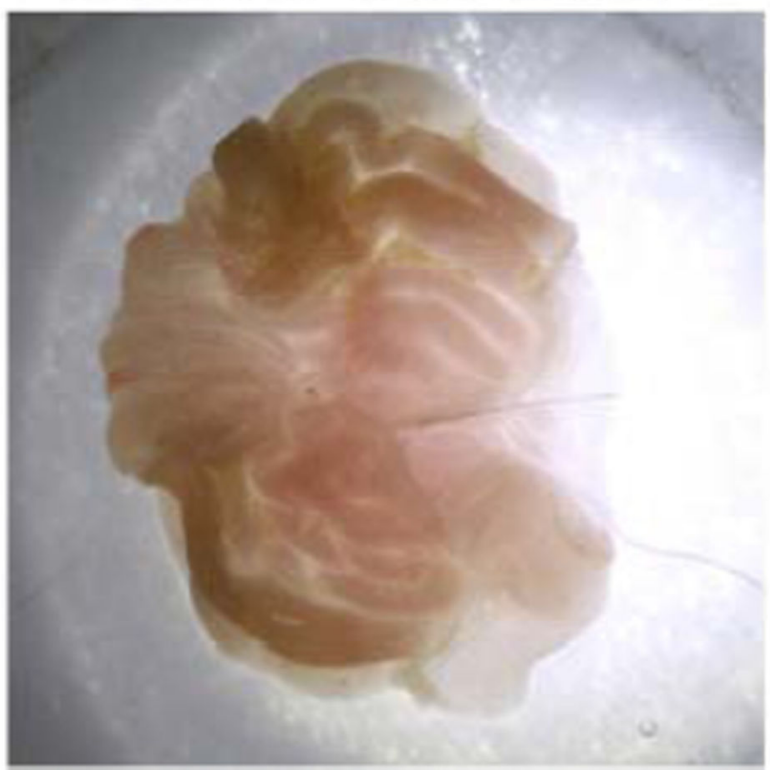

Fig. 2.

Representative images of mouse stomachs. Vehicle or $\Delta^{9}$-THC $(1 \mathrm{mg} / \mathrm{kg}$, i.p. or $5 \mathrm{mg} / \mathrm{kg}$, p.o.) was administered $1 \mathrm{~h}$ before diclofenac sodium $(100 \mathrm{mg} / \mathrm{kg}$, p.o.) was administered in fasted mice. Yellow arrows indicate hemorrhagic streaks. 

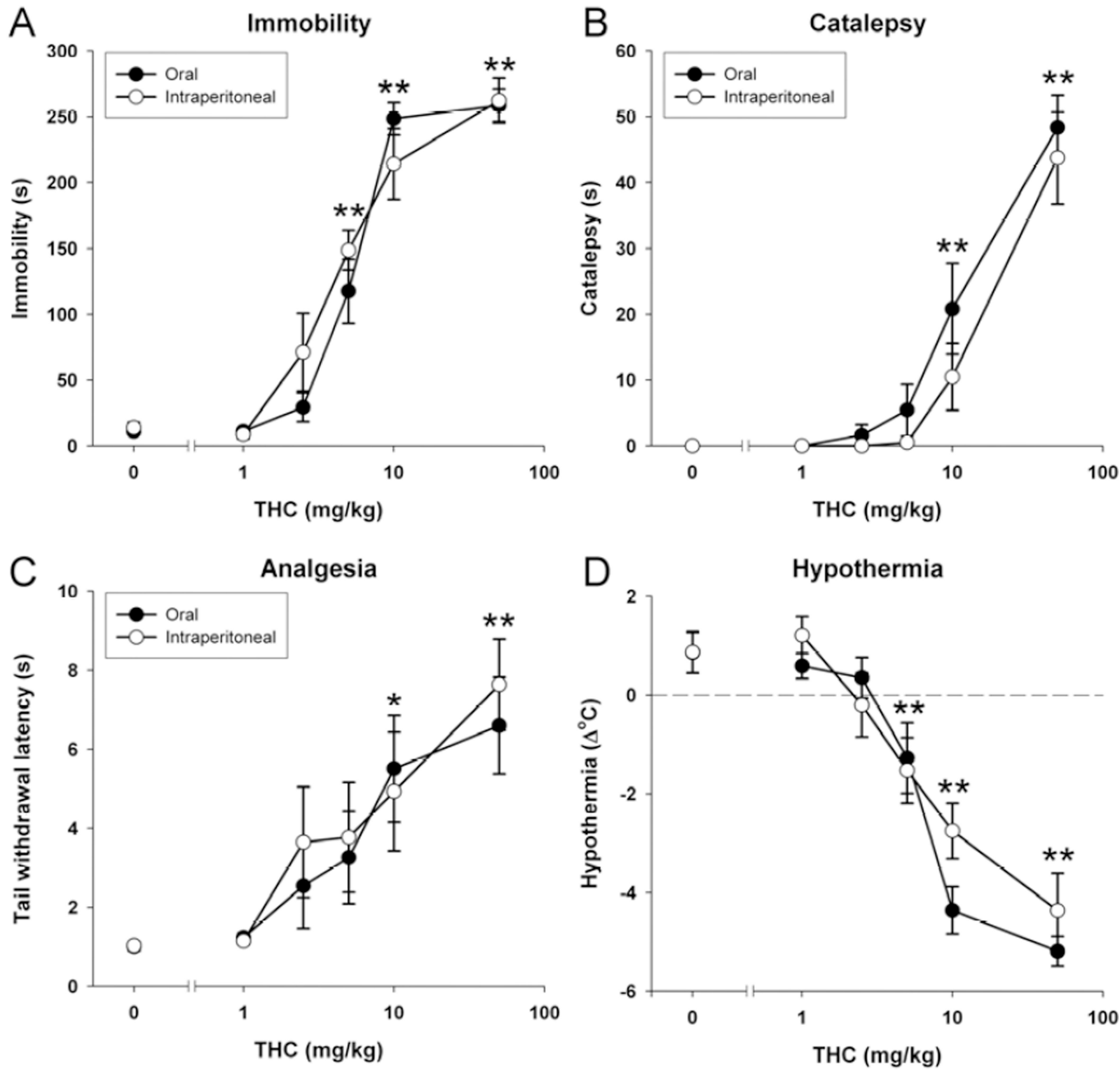

Fig. 3.

Dose-response curves of $\Delta^{9}$-THC sensitive behaviors. $\Delta^{9}$-THC was administered (i.p. or p.o.), and then assessed $1 \mathrm{~h}$ later in a battery of tests highly sensitive to the pharmacological effects of cannabinoids, including (A) spontaneous locomotor activity (B) catalepsy, (C) analgesia in the tail immersion test, and (D) hypothermia. Data presented as mean \pm S.E.M. $(\mathrm{n}=8-12)$. Open circles: intraperitoneal $\Delta^{9}$-THC; closed circles: oral $\Delta^{9}$-THC. $* \mathrm{P}<0.05$, $* * \mathrm{P}<0.01$ vs. vehicle. 


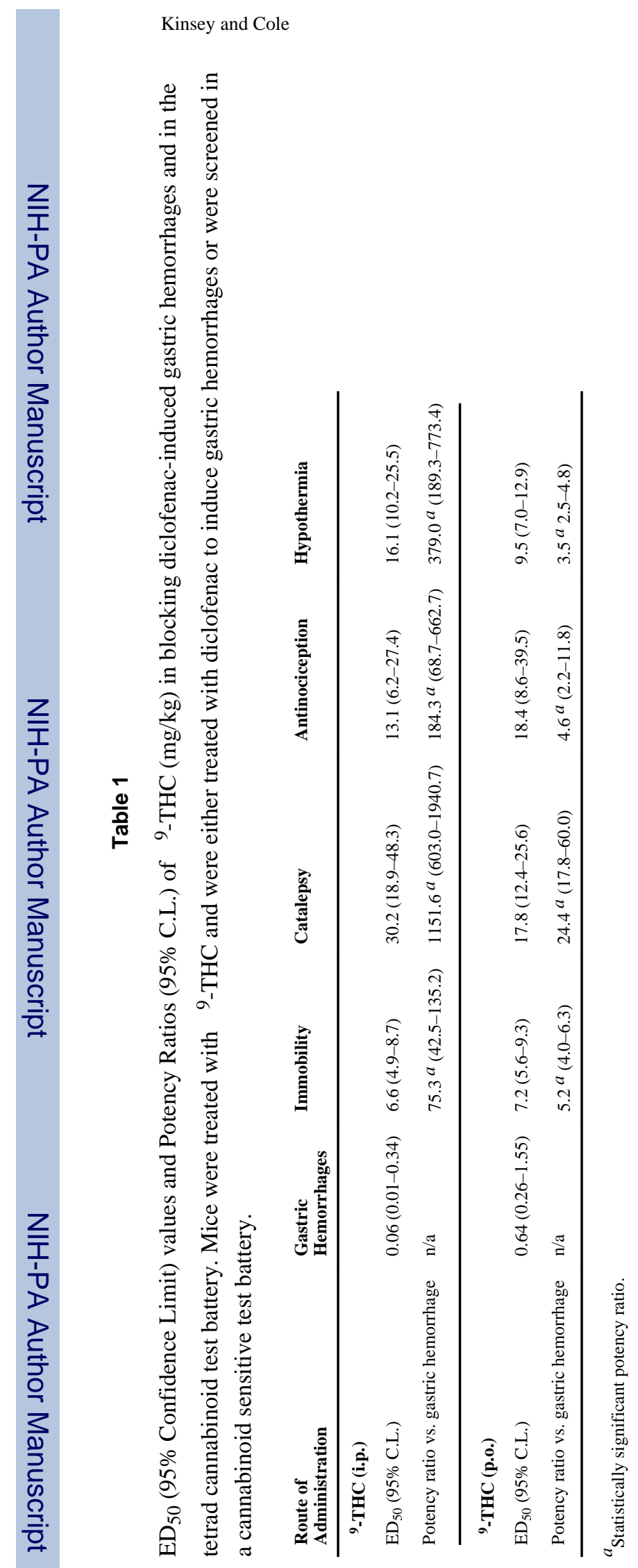

Eur J Pharmacol. Author manuscript; available in PMC 2014 September 05. 